University of Nebraska - Lincoln

DigitalCommons@University of Nebraska - Lincoln

USGS Staff -- Published Research

US Geological Survey

$4-1983$

\title{
Simulation of Solute Transport in a Chemically Reactive Heterogeneous System' Model Development and Application
}

C.W. Miller

Lawrence Berkeley Laboratory

Larry Benson

University of Colorado at Boulder, great.basin666@gmail.com

Follow this and additional works at: http:// digitalcommons.unl.edu/usgsstaffpub

Miller, C.W. and Benson, Larry, "Simulation of Solute Transport in a Chemically Reactive Heterogeneous System' Model Development and Application" (1983). USGS Staff-- Published Research. 799.

http://digitalcommons.unl.edu/usgsstaffpub/799

This Article is brought to you for free and open access by the US Geological Survey at DigitalCommons@University of Nebraska - Lincoln. It has been accepted for inclusion in USGS Staff -- Published Research by an authorized administrator of DigitalCommons@University of Nebraska - Lincoln. 


\title{
Simulation of Solute Transport in a Chemically Reactive Heterogeneous System:
}

\author{
Model Development and Application
}

\author{
C. W. Miller AND L. V. Benson \\ Earth Sciences Division, Lawrence Berkeley Laboratory, Berkeley, California 94720
}

\begin{abstract}
One-dimensional transport of solutes in a saturated porous medium has been simulated using a numerical model CHEMTRN. This model includes dispersion/diffusion, advection, ion exchange, formation of complexes in the aqueous phase, and the dissociation of water. The mass action, transport, and site constraint equations are expressed in a differential/algebraic form and solved simultaneously. In the mass action equations describing complexation and sorption processes, the activities of the species in the aqueous phase are approximated using the Davies equation. A solubility constraint can be set at the inner boundary. The model was applied to a study of the migration of strontium in groundwater. Results show that surface site competition is important when the strontium concentration is comparable to the background electrolyte concentration, in which case a constant $k_{D}$ model does not simulate the transport of chemical species adequately. In addition, the $\mathrm{pH}$ level was buffered to a level of approximately 10 near the wasteform due to the incorporation of the solubility constraint. For the particular case studied, the incorporation of aqueous complexation did not significantly enhance strontium mobility.
\end{abstract}

\section{INTRODUCTION}

The transport of chemical species in groundwater systems is of interest to a variety of earth scientists. Development of transport models that incorporate the phenomena which govern the partitioning of chemical species between aqueous and solid phases is fundamental to an understanding of processes such as ore deposition, the chemical diagenesis of sediments, and the migration of toxic chemical and nuclear wastes. A large number of chemical transport models, of varying degrees of complexity, have been devised for the purpose of providing this capability (see, for instance, Holly and Fenske [1968], Routson and Serne [1972], Rubin and James [1973], Ahlstrom et al. [1977], Grove and Wood [1979], Strickert et al. [1979], Charbeneau [1981], and Valocchi et al. [1981]). Anderson [1979] has reviewed much of this literature up to 1978.

Two methods have been applied to chemical transport models. One method integrates existing codes for equilibrium distributions of species with transport algorithms in a two-step procedure. This method was used, for example, by Rouston and Serne [1972], Ahlstrom et al. [1977], Grove and Wood [1979], Strickert et al. [1979], and more recently, by Walsh et al. [1982]. Applications of this method can be differentiated by the manner in which transport by dispersion/diffusion is accounted for. Thus Ahlstrom et al. [1977] used a random walk procedure, while Grove and Wood [1979] solved the nonreacting advective-dispersive transport equation.

The second method is based on a one-step procedure which consists of solving simultaneously a system of equations describing chemical reactions and advective-dispersive transport with interphase mass transfer. In its simplest form, exemplified by the work of Holly and Fenske [1968], the method assumes uncoupled equilibrium exchange of noncompeting solutes, each possessing a constant distribution coefficient $k_{D}$. In this case the system of simultaneous equations reduces to a set of independent, linear, partial differential transport equations, one for each exchanging solute. In its more advanced form, exemplified

This paper is not subject to U.S. copyright. Published in 1983 by the American Geophysical Union.

Paper number 2W1811. by the work of Rubin and James [1973] and Valocchi et al. [1981], the method is more soundly based on chemical and thermodynamic principles and leads to a system of simultaneous, nonlinear, partial differential equations coupled to a set of mass action equations and a site constraint equation.

The transport of dissolved chemical species through a watersaturated porous medium is influenced by a wide variety of reversible and irreversible chemical and physical processes, including dispersion/diffusion, advection, formation of complexes in the aqueous phase, sorption, and chemical precipitation. In general, current models do not incorporate complete descriptions of the entire set of phenomena known to affect rates of chemical migration. More particularly, existing models which incorporate certain individual chemical processes suffer from omission of other possibly significant processes. Thus the reliability of predictions made through the application of these models is, at best, difficult to assess.

The principal objective of our work is the creation of a general chemical transport model which includes all chemical mechanisms necessary for accurate calculation of the migration of chemical species in chemically reactive rock-water systems. With this in mind a very flexible chemical transport model was written. Various algorithms which describe physical and chemical phenomena pertinent to a particular geochemical system can be added to this model with little change. These phenomena can be either reversible or irreversible in nature.

At present the model CHEMTRN includes dispersion/diffusion, advection, sorption of ions and complexes onto the solid matrix, formation of complexes in the aqueous phase, and the dissociation of water. It advances the work of Rubin and James [1973] and Valocchi et al. [1981] (who solve the ion exchange problem for a limited number of exchanging species) by including complexation, multicomponent sorption, and water dissociation. For the time being only one-dimensional flow has been considered. However, CHEMTRN can be applied directly to systems characterized by two- or three-dimensional flow fields by using a two-step procedure. Streamlines of the groundwater flow field are first determined using a sophisticated flow model such as PT [Bodvarsson, 1981]. Then CHEMTRN is used to solve for chemical concentrations along any of these 
streamlines. However, this procedure ignores transverse dispersion.

\section{Basic Equations}

The formation of a complex $B_{i}{ }^{n} c_{1}$ in the aqueous phase from a basis set of species $A_{j}{ }^{{ }_{j}}$,

$$
a_{i 1} A_{1}^{n_{1}}+a_{i 2} A_{2}{ }^{n_{2}}+\cdots+a_{i N} A_{N}^{n_{N}}=B_{i}^{n_{c_{i}}}
$$

is described at equilibrium by the mass action expression

$$
K_{i}=\left[B_{i}{ }^{n_{c_{1}}}\right]\left(\prod_{j=1}^{N_{b}}\left[A_{j}^{n_{j}}\right]^{a_{i j}}\right)^{-1}
$$

where the square brackets denote the thermodynamic activity of the dissolved species, $K_{i}$ is the equilibrium constant, $a_{i j}$ is the stoichiometric reaction coefficient, $n_{j}$ is the charge of the basis species, and $n_{c_{1}}$ is the charge of the complex. The activities are approximated using the relation:

$$
\left[A_{j}{ }^{n j}\right]=\gamma_{j} m_{j}
$$

where $\gamma_{j}$ is an activity coefficient and $m_{j}$ is the concentration (molal) of solute species. Equation (1) then reduces to

$$
K_{i}=\gamma_{c_{i}} m_{c_{i}}\left(\prod_{j=1}^{N_{b}}\left(\gamma_{j} m_{j}\right)^{a_{j} j}\right)^{-1}
$$

where $m_{c_{i}}$ is the molal concentration of the complex $B_{i}{ }^{{ }^{c i} i}$.

The activity coefficients of the aqueous species (basis species and complexes) are functions of temperature, pressure, and chemical composition. For this work they are approximated using the Davies equation [Stumm and Morgan, 1970],

$$
\log _{10} \gamma_{j}=-\frac{1}{2} n_{j}^{2}\left(\frac{\sqrt{I}}{1+\sqrt{I}}-0.3 I\right)
$$

where $I$ is the ionic strength, defined as

$$
I=\frac{1}{2}\left(\sum_{j=1}^{N_{b}} n_{j}^{2} m_{j}+\sum_{i=1}^{N_{c}} n_{c_{i}}{ }^{2} m_{c_{i}}\right)
$$

where $N_{b}$ is the total number of basis species and $N_{c}$ is the number of complexes in the aqueous phase. The activity of water is taken to be unity. (Note that $0.3 I$ has been used in the Davies equation instead of $0.2 I$, as in the footnote on p. 83 of Stumm and Morgan [1970].)

The sorption of ions and complexes on the solid phase is modeled by an ion exchange process. For species $A_{1}{ }^{n_{1}}$ exchanging with species $A_{2}{ }^{{ }^{2}}$,

$$
n_{2} A_{1}{ }^{n 1}(a q)+n_{1} \bar{A}_{2}=n_{2} \bar{A}_{1}+n_{1} A_{2}{ }^{n_{2}}(a q)
$$

where $\bar{A}_{j}$ denotes the sorbed component. This reaction can also be described by a thermodynamic equilibrium constant,

$$
K_{\mathrm{eq}}=\frac{\left[\bar{A}_{1}\right]^{n_{2}}\left[A_{2}{ }^{n_{2}}\right]^{n_{1}}}{\left[A_{1}{ }^{n_{1}}\right]^{n_{2}}\left[\bar{A}_{2}\right]^{n_{1}}}
$$

where the square brackets again denote activities and are expressed as $\gamma_{j} m_{j}$. At present, because of the lack of data for activity coefficients for the surface phase, an ideal solution is assumed where

$$
\left[\bar{A}_{j}\right]=\frac{\bar{m}_{j}}{\bar{m}_{T}}
$$

and where $\bar{m}_{j}$ is the concentration of species $j$ on the surface phase and $\bar{m}_{T}$ is the total concentration sorbed on the surface phase given by

$$
\bar{m}_{T}=\sum_{j=1}^{\bar{N}_{b}} \bar{m}_{j}+\sum_{i=1}^{\bar{N}_{c}} \bar{m}_{c_{i}}
$$

$\bar{N}_{b}$ is the total number of sorbed basis species, $\bar{N}_{c}$ is the total number of sorbed complexes, and $\bar{m}_{c_{i}}$ is the concentration of sorbed complexes. The units of $\bar{m}_{j}, \bar{m}_{c_{i}}$, and $\bar{m}_{T}$ are expressed as moles per kilogram of solution. These units can be related to the more conventional ones (moles per gram of solid) used for the sorbed phase by dividing $\bar{m}_{j}$ by $\rho_{s}(1-\phi) 10^{3} /\left(\rho_{w} \phi\right)$, where $\rho_{s}$ is the density of the solid phase in grams per cubic centimeter, $\rho_{w}$ is the density of solution in kilograms per liter, and $\phi$ is the porosity of the porous medium. An effective equilibrium constant $K_{1}{ }^{2}$ is used to model the ion exchange process, and (6) is replaced by

$$
K_{1}{ }^{2}=\left[\frac{\left(\bar{m}_{1} / \bar{m}_{T}\right)^{n_{2}}}{\left(\gamma_{1} m_{1}\right)^{n_{2}}}\right]\left[\frac{\left(\gamma_{2} m_{2}\right)^{n_{1}}}{\left(\bar{m}_{2} / \bar{m}_{T}\right)^{n_{1}}}\right]
$$

In addition, it is assumed that the total number of equivalents of surface sites per kilogram of solution, $N_{s}$, available for ion exchange is constant:

$$
N_{s}=\sum_{j=1}^{\bar{N}_{b}} n_{j} \bar{m}_{j}+\sum_{i=1}^{N_{c}} n_{c_{i}} \bar{m}_{c_{i}}
$$

This concentration of sites on a solid whose surface density is constant over the $p \mathrm{H}$ range of interest can be determined from the cation exchange capacity (CEC) (milliequivalents per gram of solid) or

$$
N_{s}=(\mathrm{CEC}) \frac{\rho_{s}(1-\phi)}{\rho_{w} \phi}
$$

Both complexed and bare forms of an ionic component are subject to transport by dispersive/diffusive and advective processes. These forms are also subject to sorption processes and are therefore associated with the surface phase at least a portion of the time. The total concentration of each basis species (e.g., $\mathrm{Na}^{+}, \mathrm{Ca}^{2+}$, etc.) present in the aqueous phase is

$$
W_{j}=m_{j}+\sum_{i=1}^{N_{c}} a_{i j} m_{c_{t}}
$$

and the total sorbed concentration of each basis species is

$$
\bar{W}_{j}=\bar{m}_{j}+\sum_{i=1}^{\bar{N}_{c}} a_{i j} \bar{m}_{c_{i}}
$$

When considering the mass balance of a species on a volume element of the fluid (in contrast to the porous medium), the one-dimensional transport of $W_{j}$ is written as

$$
L\left(W_{j}\right)=-\frac{\partial}{\partial t} \bar{W}_{j}
$$

where the operator $L$ is defined as

$$
L=\left(\frac{\partial}{\partial t}-D \frac{\partial^{2}}{\partial x^{2}}+v \frac{\partial}{\partial x}\right)
$$

If a species sorbs neither in the bare ion nor complexed state, then $\bar{W}_{j}=0 . D$ is the dispersion/diffusion coefficient and $v$ is the actual fluid velocity, i.e., the Darcy velocity divided by the porosity. Except for the field simulation study given below, $D$ and $v$ are assumed to be constant. For the field case, $D$ is set proportional to $v$, with $v$ assumed to be inversely proportional to $r$, the radius vector.

The number of unknowns is $N_{b}+\bar{N}_{b}+N_{c}+\bar{N}_{c}$. Therefore an equal number of equations is needed for solution of this 
system. For (14), $j=1, \ldots, N_{b}$, giving $N_{b}$ equations. The mass action relation (3) provides $N_{c}$ equations for the complexes. There are $\bar{N}_{b}+\bar{N}_{c}-1$ relationships of the form of (9), and (10) provides the final relationship needed. The activity coefficients are given by (4), and $\bar{m}_{T}$ is defined by (8). Therefore a sufficient number of equations exist and can be used to determine $m_{j}, \bar{m}_{j}$, $m_{c_{1}}$, and $\bar{m}_{c_{1}}$.

\section{SOlution Procedure}

The partial differential equations (14) are discretized in space leading to a set of ordinary differential equations (ODE's):

$$
\begin{aligned}
\frac{d}{d t} W_{j, n}+\frac{d}{d t} \bar{W}_{J, n}=\frac{D}{\Delta x^{2}}\left(W_{J, n+1}\right. & \left.-2 W_{j, n}+W_{j, n-1}\right) \\
& -\frac{v}{\Delta x}\left(W_{j, n}-W_{j, n-1}\right)
\end{aligned}
$$

where $j$ denotes the species and $n$ is the spatial position. The advection term has been expressed using an upwind differencing method. The reason for this choice and some alternative approaches will be discussed below.

The system of equations (3), (9), (10), and (15) forms a set of differential/algebraic equations (DAE's) which fit the form

$$
G(m, t) \frac{d m}{d t}+F(m, t)=0
$$

where $m$ is a vector which contains all the unknowns $\left(m_{j}, \bar{m}_{j}\right.$, $\left.m_{c l}, \bar{m}_{c l}\right)$ at all the node points. The matrix $G$ is singular, because $g_{j, n}=0$ when the mass action equations (3) and (9) and the site constraint equation (10) are fit to the form of (16).

Kee and Miller [1980] have used this approach to model chemically reacting flow in boundary layers. They give a detailed procedure for solving these types of differential/algebraic problems, pointing out that there are a number of methods of discretizing $m$ in time. For the work done here, a backward Euler method was used, i.e.,

$$
G\left(m^{l+1}, t\right) \frac{\left(m^{l+1}-m^{l}\right)}{\Delta t}+F\left(m^{l+1}, t\right)=0
$$

where $l$ denotes the old time level and $l+1$ denotes the new time level. A number of more sophisticated DAE solvers based on more than one old time level are available, including that of Hindmarsh [1980] and Petzold [1981]. However, the model being developed will include precipitation in the near future, and when precipitates form, the number of unknowns increases. Methods based on using derivatives at several time steps such as those employed by Hindmarsh [1980] would have to be restarted. Because of the future inclusion of precipitation in the model, the simpler backward differencing method was used.

An advantage of using just two time levels is that it is possible to modify the backward Euler method slightly by evaluating the advection terms at the old time level using an upwind differencing method, maintaining the physical significance of this term, i.e., information is transported in the direction of the flow, while still evaluating the diffusion terms at the new time level. (Central differencing, as well as the finite element methods of Rubin and James [1973] and those of Valocchi et al. [1981], allow information to be advected upstream.) However, the upwind differencing scheme used in CHEMTRN for the advection term does introduce artificial diffusion with a coefficient of $(v \Delta x / 2)(1-c)$, where $c$ is the Courant number and is equal to $v \Delta t / \Delta x$. This dispersion, though, can be thought of as contributing to the physical dispersion term. It is directly proportional to the velocity in the same manner in which the physical dispersion is formulated. The numerical dispersion can be minimized by using a time step such that $c=1$; then $\Delta t=\Delta x / v$, although this restriction can be rather stringent. However, for a variable grid spacing, one cannot necessarily have $c=1$ throughout the entire grid. In this case, if numerical dispersion is comparable or greater than physical dispersion, alternate differencing methods [Roache, 1972] may have to be used for the advection term. Except for the field simulation study reported here, the numerical dispersion contributes about $10 \%$ to the overall dispersion. For the field simulation study the numerical dispersion contributed about $25 \%$.

To solve the system of equations, a Newton-Raphson iteration technique was used. The Newton-Raphson method solves the set of equations by first guessing the values of the unknowns at the new time level and then calculating the residue for all the equations for that guess, i.e.,

$$
\begin{aligned}
& G\left(m^{l+1, k}, t\right)\left(\frac{m^{l+1, k}-m^{l}}{\Delta t}\right) \\
&+F\left(m^{l+1, k}, t\right)=R\left(m^{l+1, k}, t\right)
\end{aligned}
$$

where $k$ denotes the iteration number and $R$ is a matrix containing the residues of the equations. A new guess is obtained by first calculating the Jacobian $J$, where $J=\partial R / \partial m$, and then using the Jacobian to predict the value of the unknowns at the new time level:

$$
J \Delta m=J\left(m^{l+1, k+1}-m^{l+1, k}\right)=-R\left(m^{I+1, k}\right)
$$

Since one-dimensional flow is being modeled, any component of the residue vector will be a function of the $m$ at that node point and the neighboring node points resulting in a block tridiagonal Jacobian matrix. The linear system of equations (18) is solved with LU decomposition where the Jacobian is factored into lower (L) and upper (U) triangular matrices. A software package written by Hindmarsh [1977] was used both to perform the LU decomposition and to solve the set of equations. To save time, the Jacobian is not necessarily evaluated at every time step [Kee and Miller, 1980]. The iterations of (19) continue until the change in the new values of $m$ are less than the specified error tolerance. If convergence is not obtained in a reasonable number of iterations, a new Jacobian is calculated. If convergence is still not obtained, the time step is reduced. When convergence is obtained within a specified number of iterations, the time step is increased.

Because the matrix $G$ is never inverted, it can be singular. New chemical reactions are handled by calculating the residues of the new equations describing the reactions. The calculation of the Jacobian is done numerically and therefore is independent of the types of chemical reactions considered. Nonequilibrium chemistry can be considered by replacing the calculation of the residues of the mass action equations with those of the residues of kinetic rate equations, and radioactive decay can be included by adding a decay term to the transport equation.

The matrix $G$ is never stored itself, just the residues for each guess. The Jacobian requires the calculation and the storage of the changes in residue of each equation with respect to the changes in all the unknowns at a node point and at the two neighboring node points. Although only the nonzero block matrices are stored, this storage requirement can be excessive for some computers. It is possible to break up the Jacobian matrix into several different blocks and then store these blocks separately. For example, this procedure helps to overcome some of the storage limitations of the $7600 \mathrm{CDC}$ computer which was used for these calculations. 


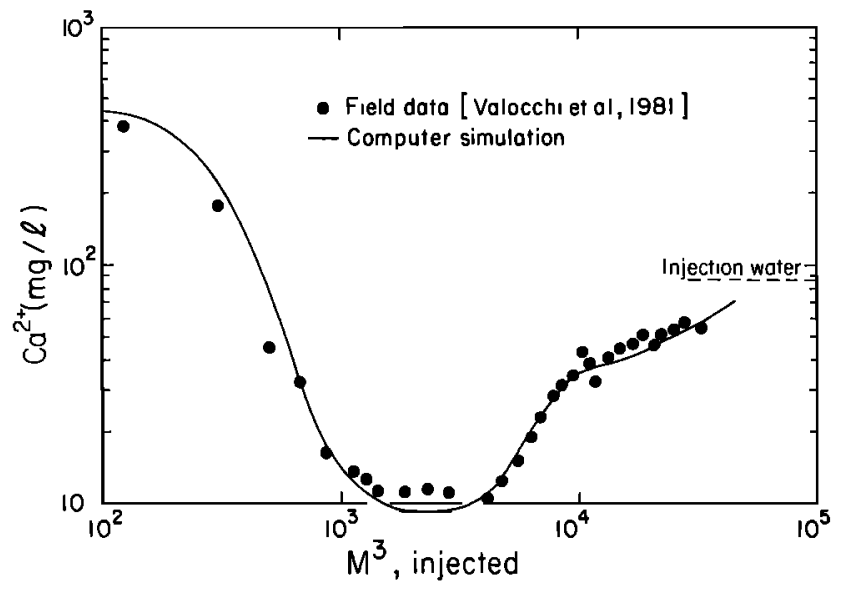

Fig. 1a. Comparison of field test [Valocchi et al., 1981] with numerical simulation using CHEMTRN for the exchanging ion $\mathrm{Ca}^{2+}$.

For the examples considered below, uniform conditions are assumed throughout the porous medium initially. The total aqueous concentration of each species is given and (3) is used to determine an equilibrium distribution of species. The concentration of sorbed ions is determined from the mass action equations (9) and the total concentration of sites available for sorption (10).

Different boundary conditions are possible with CHEMTRN. The flexibility is obtained by expressing the boundary conditions in the form of (16) as stated by Kee and Miller [1980]. Both time-dependent and steady state boundary conditions can be studied. For the cases considered below, a concentration boundary condition was used at the inner boundary where the magnitude of the concentration was determined by a solubility constraint:

$$
K_{12}=\left[A_{1}\right]\left[A_{2}\right]
$$

where $K_{12}$ is an equilibrium solubility product. A semi-infinite system was modeled by imposing a no-flux condition at the outermost nodes of a finite grid. This boundary condition was imposed far enough away from the inner nodes so it did not affect the solution at these points.

An additional aspect of CHEMTRN is the treatment of the hydrogen ion activity. In most chemical systems the hydrogen ion can be considered a master variable since many chemical reactions depend on its activity. In an aqueous solution the dissociation of water is an important source of hydrogen ions, i.e.,

$$
\mathrm{H}_{2} \mathrm{O}=\mathrm{H}^{+}+\mathrm{OH}^{-}
$$

Most available chemical transport models do not incorporate this reaction. Since calculations involving solubility, sorption, and complexation often depend on $p \mathrm{H}$, failure to account for the dissociation of water can result in incorrect estimates of chemical migration. Therefore, we have included this chemical phenomenon in CHEMTRN.

To avoid convergence problems, CHEMTRN solves for a dummy concentration $y$, defined by

$$
y=m_{\mathrm{H}^{+}}-m_{\mathrm{OH}^{-}}
$$

This method is employed because a mass balance equation for either $\mathrm{H}^{+}$or $\mathrm{OH}^{-}$must include the concentration of water, and a change in the latter is extremely small relative to changes in the hydrogen or hydroxyl ion concentrations. To solve for $y$, a slight modification must be made to the mass balance equations for $\mathrm{H}^{+}$and $\mathrm{OH}^{-}$. The mass balance equation for the hydrogen ion is

$$
L\left(m_{\mathrm{H}^{+}}+\sum_{i} a_{i, \mathrm{H}^{+}} m_{c_{i}}\right)+\frac{\partial}{\partial t} \bar{W}_{\mathrm{H}^{+}}=-L\left(m_{\mathrm{H}_{2} \mathrm{O}}\right)
$$

and for the hydroxyl ion

$$
L\left(m_{\mathrm{OH}-}+\sum_{i} a_{i, \mathrm{OH}}-m_{c_{i}}\right)=-L\left(m_{\mathrm{H}_{2} \mathrm{O}}\right)
$$

If (23) is subtracted from (22), the result is

$$
L\left[y+\sum_{i}\left(a_{i, \mathrm{H}^{+}}-a_{i, \mathrm{OH}^{-}}\right) m_{c_{l}}\right]+\frac{\partial}{\partial t} \bar{W}_{\mathrm{H}^{+}}=0
$$

An additional relationship is obtained from the mass action equation for the dissociation of water:

$$
\left[\mathrm{H}^{+}\right]\left[\mathrm{OH}^{-}\right]=K_{w}
$$

where $K_{w}$ has the value of $10^{-13.99}$ at $25^{\circ} \mathrm{C}$.

\section{Field Test Simulation}

To check the ability of the numerical model CHEMTRN to model chemical transport, the code was used to simulate a field test described in the paper by Valocchi et al. [1981] where treated municipal wastewater effluent was injected into a shallow aquifer in the Palo Alto (California) Baylands region. The principal chemical mechanism thought to govern transport here is ion exchange between $\mathrm{Na}^{+}, \mathrm{Ca}^{2+}$, and $\mathrm{Mg}^{2+}$. Field data used for this simulation were obtained from Valocchi et al. [1981]. More data are available from Roberts et al. [1978] and Charbeneau and Street [1978], referenced by Valocchi et al. [1981].

A simulation was done for the fluid arriving at well $\mathrm{S} 23,16 \mathrm{~m}$ from the injection site. The initial composition of groundwater in this region consisted of $5700 \mathrm{mg} / \mathrm{Cl}^{-}, 1990 \mathrm{mg} / 1 \mathrm{Na}^{+}, 436$ $\mathrm{mg} / \mathrm{Mg}^{2+}$, and $444 \mathrm{mg} / \mathrm{l} \mathrm{Ca}^{2+}$. The effluent water was injected at an average rate of $21 \mathrm{~m}^{3} / \mathrm{hr}$ and had an average composition of $320 \mathrm{mg} / 1 \mathrm{Cl}^{-}, 216 \mathrm{mg} / 1 \mathrm{Na}^{+}, 12 \mathrm{mg} / 1 \mathrm{Mg}^{2+}$, and $85 \mathrm{mg} / \mathrm{l}$ $\mathrm{Ca}^{2+}$. As given by Valocchi et al. [1981], the aquifer thickness was taken to be $2 \mathrm{~m}$, the solid matrix density was $2500 \mathrm{~g} / \mathrm{l}$, the CEC was $0.1 \mathrm{meq} / \mathrm{g}$, and the porosity was $25 \%$.

Figures $1 a$ and $1 b$ are comparisons of the field measurements of the exchanging ions $\mathrm{Ca}^{2+}$ and $\mathrm{Mg}^{2+}$ at well $\mathrm{S} 23$ and the simulations of these measurements using CHEMTRN. For this

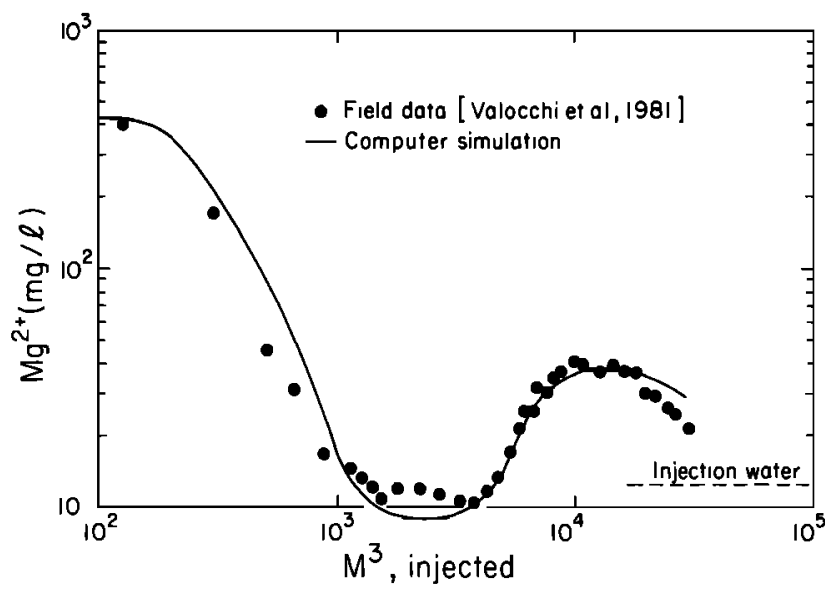

Fig. 1b. Comparison of field test [Valocchi et al., 1981] with numerical simulation using CHEMTRN for the exchanging ion $\mathbf{M g}^{2+}$. 
simulation, radial flow was assumed with the fluid velocity proportional to $Q /(2 \pi b \phi r) ; Q$ is the injection rate and $b$ is the aquifer thickness. The dispersion coefficient used, including the numerical dispersion, was about $1.3 v$ for this example. The selectivity coefficient used for the exchange reaction of $\mathbf{M g}^{2+}$ replacing $\mathrm{Na}^{+}$was 0.57 and that for $\mathrm{Ca}^{2+}$ replacing $\mathrm{Na}^{+}$was 1.0. Note that the selectivity coefficients in CHEMTRN are defined by using a mole fraction convention instead of an equivalent fraction convention, as used by Valocchi et al. [1981]. The selectivity coefficients used here should be multiplied by about 2 for comparison with those of Valocchi et al. The results of the simulation are encouraging given the fact that one-dimensional flow with only longitudinal dispersivity was assumed. Additional data on the $\mathrm{SO}_{4}{ }^{2-}, \mathrm{HCO}_{3}{ }^{-}, \mathrm{CO}_{3}{ }^{2-}$, and $\mathrm{H}^{+}$ion concentrations are necessary to assess the importance of complexation effects on the transport of $\mathrm{Ca}^{2+}$ and $\mathrm{Mg}^{2+}$.

\section{ApPlication to Contaminant Transport}

Many workers in the area of contaminant transport have assumed that contaminant retardation can be calculated using a constant retardation factor. This factor is related to the amount of a chemical element sorbed on the solid and the amount of the same species left in the liquid by the expression

$$
\bar{c}=k_{D} c
$$

where $\bar{c}$ is in moles per gram of solid, $c$ is in moles per cubic centimeter of solution, and $k_{D}$ (in cubic centimeters of solution per gram of solid) is commonly known as the distribution coefficient. Elementary ion exchange theory predicts that the distribution coefficient is approximately independent of the concentration of the ion of interest when the latter is extremely low relative both to the concentration of the supporting electrolyte and the cation exchange capacity. Under these conditions the ionic strength of the solution is determined mainly by the supporting electrolyte and is approximately constant; therefore activity coefficients of both sorbed and dissolved species remain constant. In addition, since the anionic composition of the solution remains approximately constant, the degree and effects of complexation are invariant.

For example, given a binary ion exchange of equally charged ionic species, the distribution coefficients are given by

$$
k_{D_{1}}=\frac{10^{-3} \mathrm{CEC}}{n\left[c_{1}+K_{\mathrm{eq}}^{-1}\left(\gamma_{2} c_{2} / \gamma_{1}\right)\right]} \quad k_{D_{2}}=\frac{10^{-3} \mathrm{CEC}}{n\left[c_{2}+K_{\mathrm{eq}}\left(\gamma_{1} c_{1} / \gamma_{2}\right)\right]}
$$

where $n$ is the ionic charge, $K_{\text {eq }}$ is the ion exchange equilibrium constant for the reaction

$$
A_{1}{ }^{n}(a q)+\bar{A}_{2}=\bar{A}_{1}+A_{2}{ }^{n}(a q)
$$

and the units of $c_{1}$ and $c_{2}$ are as given above. If $c_{2} \ll c_{1}$ and remains so, then site competition is not important and the distribution coefficients reduce to

$$
k_{D_{1}} \approx \frac{10^{-3} \mathrm{CEC}}{n c_{1}} \quad k_{D_{2}} \approx \frac{10^{-3} \mathrm{CEC}}{n K_{\mathrm{eq}}\left(\gamma_{1} c_{1} / \gamma_{2}\right)}
$$

which are not a function of $c_{2}$. However, when the aqueous phase concentrations of sorbable ions are comparable, then site competition, complexation, and ionic strength effects are expected to result in variable distribution coefficients.

Many solids common to natural systems (e.g., silica) exhibit surface amphoterism, i.e., they possess ionizable surface sites, the amounts and types of which are determined by the $p \mathrm{H}$ of the surrounding aqueous solution. For these materials, sorp- tion can be thought of as taking place by surface ionization and complexation [Davis et al., 1978]. Distribution coefficients in such systems may be strong functions of $p \mathrm{H}$ and solution composition even when contaminant species are present in trace amounts. Because of these reasons, it is important that we understand the effects of chemical mechanisms on the partitioning of contaminant and major species between the aqueous and solid phases making up the environment surrounding the contaminant-bearing wasteform.

CHEMTRN was used to investigate the magnitudes of various chemical processes on the transport of contaminant species through a porous medium having ion exchange properties. One-dimensional flow was assumed. A contaminant source function (wasteform) is located at $x=0$ and is open to the groundwater system. Although there exist many contaminant species that could be studied, the decision was made to simulate the transport of strontium and its complexes. Strontium is not an important element with respect to toxic chemical waste migration, although it is a common constituent of both highand low-level nuclear wastes. It was chosen primarily because thermodynamic data with regard to its speciation (complexation), solubility, and ion exchange behavior were available or could be approximated. In addition, its transport behavior should generally be illustrative of the transport behavior of a large proportion of the alkaline earth family of elements.

In order to test the effects of bulk fluid composition on strontium transport, the initial groundwater (supporting electrolyte) composition was varied. The supporting electrolyte consisted of $\mathrm{NaCl}$ or mixtures of $\mathrm{NaCl}$ and $\mathrm{CaCl}_{2}$. In all cases, except for the last example, a background level of $10^{-12} \mathrm{M}$ (units of moles per kilograms of solution) $\mathrm{SrCO}_{3}{ }^{\circ}$ was used. In the last case the background level of carbonate was increased to a level more typical of a groundwater system.

At the canister, a constant concentration boundary condition was assumed. However, the actual concentration level for each situation was determined by using the strontianite $\left(\mathrm{SrCO}_{3}\right)$ solubility constraint at $25^{\circ} \mathrm{C}$

$$
\left[\mathrm{Sr}^{2+}\right]\left[\mathrm{CO}_{3}{ }^{2-}\right]=10^{-9.25}
$$

along with the definition of the activities (2). Because of the response of $\gamma_{\mathrm{Sr}^{2}+}$ and $\gamma_{\mathrm{CO}_{3}{ }^{2}}$ to variation in initial groundwater composition, the concentration of strontium at the boundary in equilibrium with strontianite was different for the various cases considered. As the ionic strength of groundwater is increased, the activity coefficients of $\mathrm{Sr}^{2+}$ and $\mathrm{CO}_{3}{ }^{2-}$ decrease. In order to maintain the relation indicated by (26), the concentrations of both $\mathrm{Sr}^{2+}$ and $\mathrm{CO}_{3}{ }^{2-}$ must therefore increase. The second boundary condition used was a zero-flux condition $(\partial m / \partial x=0)$ that was assumed to hold at a distance far from the canister.

Several different cases were run to illustrate the relative importance of the different chemical processes. In the following examples, a diffusion/dispersion coefficient of $0.035 \mathrm{~m}^{2} / \mathrm{yr}$, a Darcy velocity of $0.04 \mathrm{~m} / \mathrm{yr}$, a porosity of $40 \%$, and a solid density of $2.0 \mathrm{~g} / \mathrm{cm}^{3}$ were used. These numbers are reasonable values (although the dispersion coefficient is about an order of magnitude low) but rather arbitrary choices. The CEC of the surrounding ion exchange medium was set at a value of 0.03 $\mathrm{meq} / \mathrm{g}$ so that the difference between the transport rates of nonsorbed and sorbed species were not so great that their concentration fronts could not be displayed on the same grid. The sorptive properties of the ion exchanger correspond to a material having the ion exchange equilibrium coeflicients 


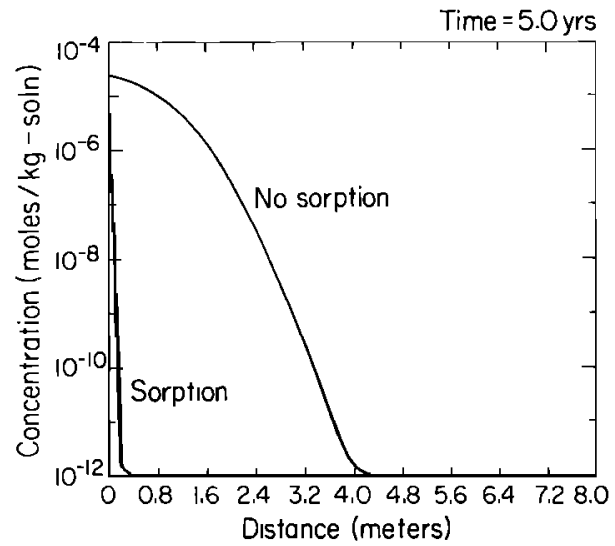

Fig. 2. Transport of $\mathrm{Sr}^{2+}$ through a porous clay illustrating the effect of sorption on radionuclide mobility.

characteristic of Camp Berteau montmorillonite. However, the CEC is only $\approx \frac{1}{30}$ of that of montmorillonite.

The first example (Figure 2) illustrates the general importance of the sorption process on contaminant retardation. The figure shows the concentration of $\mathrm{Sr}^{2+}$ in the aqueous phase as a function of distance after a time period of five years. Two cases were considered. In the first case, $\mathrm{Sr}^{2+}$ was not allowed to sorb; in the second case, $\mathrm{Sr}^{2+}$ was allowed to sorb via an ion exchange model. The initial $\mathrm{NaCl}$ background concentration used for this calculation was $0.001 \mathrm{M}$. In these calculations, aqueous phase activity coefficients were set equal to unity and complexes were not permitted to form. Therefore the boundary value concentration of $\mathrm{Sr}^{2+}$ was held at $2.37 \times 10^{-5} \mathrm{M}$ via the constraint indicated by (26). Figure 2 shows that the sorption of $\mathrm{Sr}^{2+}$ (as measured by the point where the strontium is reduced to approximately the background level) decreases the mobility of strontium by about $90 \%$. Note in this and subsequent figures that the distance traveled by a sorbable cation should be div-
TABLE 2. Chemical Reactions and Log $K$ Values at $25^{\circ} \mathrm{C}$

\begin{tabular}{|c|c|c|c|}
\hline & Reaction & $\log K$ & \\
\hline \multicolumn{4}{|c|}{ Ion Exchange* } \\
\hline $\begin{array}{l}1 . \\
2 .\end{array}$ & $\begin{array}{l}\mathrm{Na}^{+}+\overline{\mathbf{H}} \\
\frac{1}{2} \mathrm{Sr}^{2+}+\mathbf{H}\end{array}$ & $\begin{array}{l}=\mathrm{H}^{+}+\overline{\mathrm{Na}} \\
=\mathrm{H}^{+}+\overline{\mathrm{Sr}}_{1 / 2}\end{array}$ & $\begin{array}{l}-0.176 \\
-0.176\end{array}$ \\
\hline 3. & $\frac{1}{2} \mathrm{Ca}^{2+}+\overline{\mathrm{H}}$ & $=\mathrm{H}^{+}+\overline{\mathrm{Ca}}_{1 / 2}$ & -0.181 \\
\hline \multicolumn{4}{|c|}{ Complexation $\dagger$} \\
\hline & $\mathrm{Sr}^{2+}+\mathrm{CO}_{3}^{2-}$ & $=\mathrm{SrCO}_{3}{ }^{0}$ & 3.00 \\
\hline 5. & $\mathrm{Sr}^{2+}+\mathrm{OH}^{-}$ & $=\mathrm{SrOH}^{+}$ & 0.80 \\
\hline 6. & $\mathrm{Sr}^{2+}+\mathrm{H}^{+}+\mathrm{CO}_{3}{ }^{2-}$ & $=\mathrm{SrHCO}_{3}{ }^{+}$ & 11.33 \\
\hline 7. & $\mathrm{Na}^{+}+\mathrm{CO}_{3}{ }^{2-}$ & $=\mathrm{NaCO}_{3}^{-}$ & 0.96 \\
\hline 8. & $\mathrm{Na}^{+}+\mathrm{H}^{+}+\mathrm{CO}_{3}{ }^{2-}$ & $=\mathrm{NaHCO}_{3}{ }^{\mathrm{O}}$ & 1.08 \\
\hline 9. & $\mathrm{Na}^{+}+\mathrm{OH}^{-}$ & $=\mathrm{NaOH}^{0}$ & -0.21 \\
\hline 10. & $\mathrm{H}^{+}+\mathrm{CO}_{3}{ }^{2-}$ & $=\mathrm{HCO}_{3}^{-}$ & 10.30 \\
\hline 11. & $2 \mathrm{H}^{+}+\mathrm{CO}_{3}^{2-}$ & $=\mathrm{H}_{2} \mathrm{CO}_{3}^{\circ}$ & 16.7 \\
\hline 12. & $\mathrm{Ca}^{2+}+\mathrm{CO}_{3}^{2-}$ & $=\mathrm{CaCO}_{3}{ }^{\circ}$ & 3.15 \\
\hline 13. & $\mathrm{Ca}^{2+}+\mathrm{H}^{+}+\mathrm{CO}_{3}^{2-}$ & $=\mathrm{CaHCO}_{3}{ }^{+}$ & 11.33 \\
\hline 14. & $\mathrm{Ca}^{2+}+\mathrm{OH}^{-}$ & $=\mathrm{CaOH}^{+}$ & 1.32 \\
\hline \multicolumn{4}{|c|}{ Dissociation of Water } \\
\hline 15. & $\mathrm{H}_{2} \mathrm{O}$ & $=\mathbf{H}^{+}+\mathrm{OH}^{-}$ & -13.99 \\
\hline \multicolumn{4}{|c|}{ Dissolution of Strontianite } \\
\hline 16. & $\mathrm{SrCO}_{3}(\mathbf{s})$ & $=\mathrm{Sr}^{2+}+\mathrm{CO}_{3}^{2-}$ & -9.25 \\
\hline
\end{tabular}

* Benson [1980]

$\dagger$ Benson and Teague [1980]

ided by 30 in order to scale properly the transport distance of the cation relative to montmorillonite's actual CEC.

To investigate the effects of these chemical phenomena on the variability of the distribution coefficient, several calculations of strontium transport were made. There are five general categories of calculations which differ in their degree of chemical complexity (Table 1): (1) binary ion exchange of $\mathrm{Sr}^{2+}$ for $\mathrm{Na}^{+}$on a Na-loaded substrate, (2) ternary ion exchange wherein $\mathrm{Na}^{+}, \mathrm{Ca}^{2+}$, and $\mathrm{Sr}^{2+}$ ions compete for a finite number of sites initially occupied by $\mathrm{Na}^{+}$and $\mathrm{Ca}^{2+}$, (3) binary ion

TABLE 1. Input Data, Boundary Conditions, and Resultant $k_{\boldsymbol{D}}$ for Examples

\begin{tabular}{|c|c|c|c|c|c|c|c|c|}
\hline $\begin{array}{l}\text { Important } \\
\text { Chemical } \\
\text { Effects }\end{array}$ & $\begin{array}{c}\mathrm{Na}_{i}{ }^{+} \\
\text {moles/kg } \\
\text { solution } \\
\times 10^{3}\end{array}$ & $\begin{array}{c}\mathrm{Ca}_{1}{ }^{2+}, \\
\text { moles/kg } \\
\text { solution } \\
\times 10^{3}\end{array}$ & $\begin{array}{c}\mathrm{Sr}_{b}{ }^{2+} \\
\text { moles } / \mathrm{kg} \\
\text { solution } \\
\times 10^{5}\end{array}$ & $p \mathrm{H}$ & $k_{D, i}(\mathrm{Sr})$ & $k_{D, b}^{\prime}(\mathrm{Sr})$ & $k_{D, 1}^{\prime}(\mathrm{Na})$ & $k_{D, b}(\mathrm{Na})$ \\
\hline 1. Binary & 10.0 & & 2.37 & & $1 \times 10^{3}$ & 598 & 10 & 7 \\
\hline ion exchange & 1.0 & & 2.37 & & $1 \times 10^{5}$ & 1894 & 100 & 10 \\
\hline$(1,2,16)$ & 0.1 & & 2.37 & & $1 \times 10^{7}$ & 2088 & 1000 & 10 \\
\hline & 0.07 & & 2.37 & & $2 \times 10^{8}$ & 2095 & 1429 & 10 \\
\hline & 0.03 & & 2.37 & & $1 \times 10^{9}$ & 2103 & 3266 & 10 \\
\hline 2. Ternary & 1.0 & 1.0 & 2.37 & & 49 & 48 & 1.5 & 1.5 \\
\hline ion exchange & 1.0 & 0.01 & 2.37 & & 4215 & 1356 & 16.0 & 8.6 \\
\hline$(1-3,16)$ & 0.1 & 0.1 & 2.37 & & 497 & 402 & 5.0 & 4.5 \\
\hline & 0.1 & 0.01 & 2.37 & & 4920 & 1471 & 16.0 & 8.6 \\
\hline 3a. Ion exchange & 100.0 & & 6.15 & & 7 & 7 & 1 & 1 \\
\hline with complexation & 10.0 & & 3.30 & & 862 & 481 & 10 & 7 \\
\hline$(1-4,7,16)$ & 1.0 & & 2.67 & & $9.5 \times 10^{4}$ & 1686 & 100 & 10 \\
\hline 3b. Ternary ion & 100.0 & 1.0 & 6.81 & & 6 & 6 & 0.8 & 0.8 \\
\hline exchange with & 10.0 & 1.0 & 4.50 & & 42 & 40 & 1.7 & 1.7 \\
\hline $\begin{array}{l}\text { complexation } \\
(1-4,7,12,16)\end{array}$ & 1.0 & 1.0 & 4.10 & & 49 & 48 & 1.7 & 1.7 \\
\hline 4. Ion exchange & 1.0 & & 5.83 & 8 & $9.5 \times 10^{4}$ & 808 & 100 & 7 \\
\hline complexation and & 1.0 & & 4.17 & 10 & $9.5 \times 10^{4}$ & 1102 & 100 & 8 \\
\hline $\begin{array}{l}\text { water dissociation } \\
(1,2,4,5,7-11,15,16)\end{array}$ & 10.0 & & 4.17 & 8 & 861 & 339 & 10 & 5 \\
\hline $\begin{array}{l}\text { 5. Typical } \\
\text { groundwater } \\
(1-16)\end{array}$ & 1.0 & 0.5 & 4.10 & 8 & 100 & 93 & 2.4 & 2.2 \\
\hline
\end{tabular}




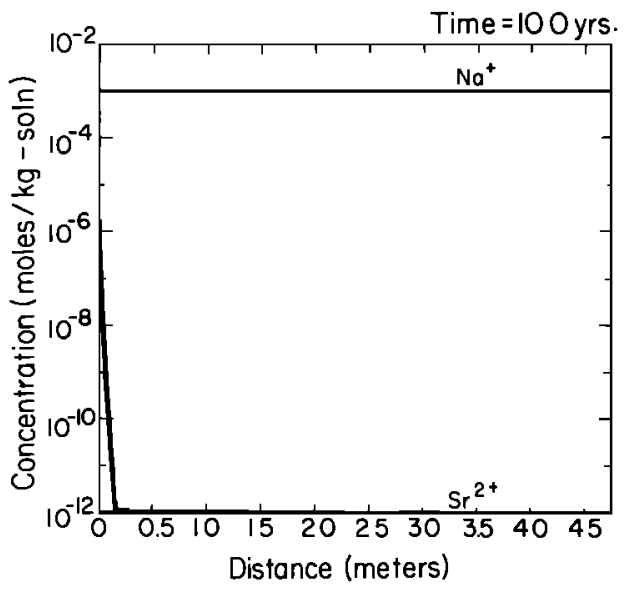

Fig. 3a. Transport of $\mathrm{Sr}^{2+}$ in background solution of $10^{-3} \mathrm{M} \mathrm{NaCl}$ including sorption on clay; concentration of $\mathrm{Na}^{+}$is also plotted.

exchange coupled with complexation in the presence of a single supporting electrolyte, (4) binary ion exchange coupled with complexation and water dissociation in the presence of a single supporting electrolyte, and (5) ternary ion exchange coupled with complexation and water dissociation for a typical groundwater system. In Table 1 are listed the initial concentrations of $\mathrm{Na}^{+}$and $\mathrm{Ca}^{2+}$, denoted as $\mathrm{Na}_{i}{ }^{+}$and $\mathrm{Ca}_{i}{ }^{2+}$, respectively. More cases are listed in each category than are actually plotted. As noted before, the initial concentration of $\mathrm{Sr}^{2+}$ is always assumed to be $10^{-12} \mathrm{M}$. Also included in the table is the total amount of $\mathrm{Sr}^{2+}$ at the boundary $\left(\mathrm{Sr}_{b}{ }^{2+}\right)$ determined from the solubility constraint. The reactions (Table 2 ) included in each case are listed in parentheses for each specific case in Table 1, as well as distribution coefficients for both $\mathrm{Sr}^{2+}$ and $\mathrm{Na}^{+}$calculated from initial concentrations $k_{D, i}{ }^{\prime}$ and from boundary concentrations $k_{D, b}{ }^{\prime}$. The prime denotes that the value of $k_{D}$ computed here is the dimensionless ratio of $\bar{m}_{j} / m_{j}$. Table 1 shows that $k_{D}$ values can vary significantly across the front where the concentration of $\mathrm{Sr}^{2+}$ changes from its initial to its boundary value.

Figures $3 a$ through $3 d$ are graphs of the aqueous concentration of $\mathrm{Sr}^{2+}$ as a function of distance. These figures illustrate the effects of different concentrations of the $\mathrm{NaCl}$ supporting electrolyte on $\mathrm{Sr}^{2+}$ transport. Reactions 1 and 2 (Table 2) are considered. It is obvious from the figures that the

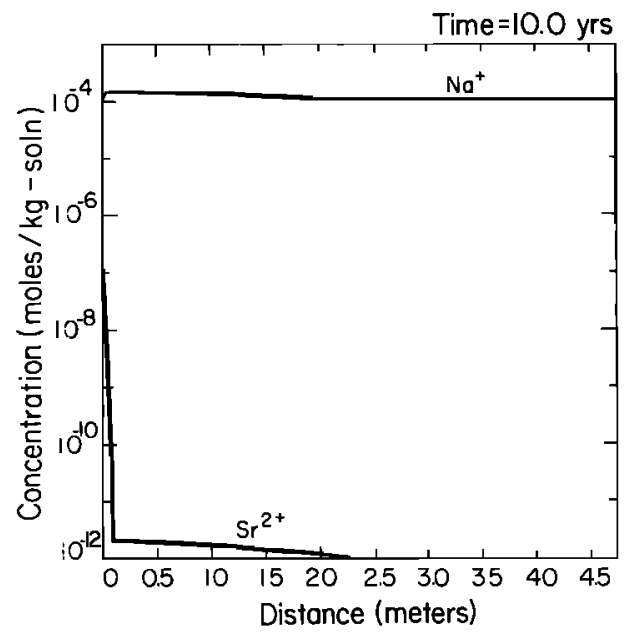

Fig. 3b. Transport of $\mathrm{Sr}^{2+}$ in background solution of $10^{-4} \mathrm{M} \mathrm{NaCl}$ including sorption on clay; concentration of $\mathrm{Na}^{+}$is also plotted.

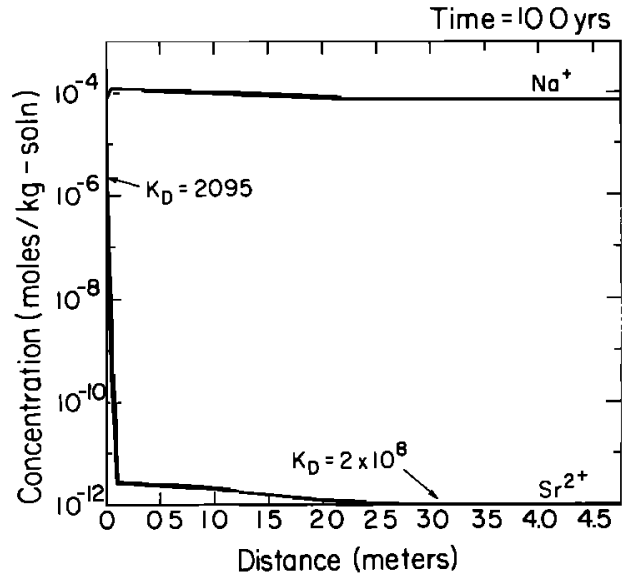

Fig. 3c. Transport of $\mathrm{Sr}^{2+}$ in background solution of $7 \times 10^{-5} \mathrm{M}$ $\mathrm{NaCl}$ including sorption on clay; concentration of $\mathrm{Na}^{+}$is also plotted.

higher the $\mathrm{NaCl}$ concentration, the lower the degree of $\mathrm{Sr}^{2+}$ sorption. Macroscopically, the tendency of an ion to be sorbed depends on its concentration in the aqueous phase relative to the concentrations of other sorbable ions, the selectivity of the sorptive substrate for an ion relative to other ions, and the number of sites on the sorptive substrate. Given similar concentrations of sorbable ions in the aqueous phase, the selectivity of $\mathrm{Sr}^{2+}$ is higher than the selectivity of $\mathrm{Na}^{+}$. However, as the concentration of $\mathrm{Na}^{+}$is increased, the enhanced selectivity for $\mathrm{Sr}^{2+}$ is outweighed by the $\mathrm{Na}^{+}$concentration effect and the distribution coefficient of $\mathrm{Sr}^{2+}$ decreases.

As the concentration of $\mathrm{Na}^{+}$is decreased relative to that of $\mathrm{Sr}^{2+}$, a very interesting phenomenon occurs. The amount of $\mathrm{Na}^{+}$displaced from the clay by $\mathrm{Sr}^{2+}$ increases the amount of $\mathrm{Na}^{+}$in the groundwater significantly, as depicted in Figures $3 a$ through $3 d$. The enhanced $\mathrm{Na}^{+}$concentration moves downstream competing with $\mathrm{Sr}^{2+}$ for the sorption sites resulting in a 'enhanced concentration effect,' wherein low levels of $\mathrm{Sr}^{2+}$ are mobilized well beyond the region of the sharp front. Note, however, that most of the strontium transported downstream is not the strontium from the waste canister but the strontium that was initially sorbed on the supporting solid matrix. This effect increases as the $\mathrm{Na}^{+}$level is decreased from $1 \times 10^{-4} \mathrm{M}$ (Figure $3 b$ ) to $7 \times 10^{-5} \mathrm{M}$ (Figure $3 c$ ) and to $3 \times 10^{-5} \mathrm{M}$ (Figure 3d). The $\mathrm{Sr}^{2+}$ ion is transmitted at a slightly higher level

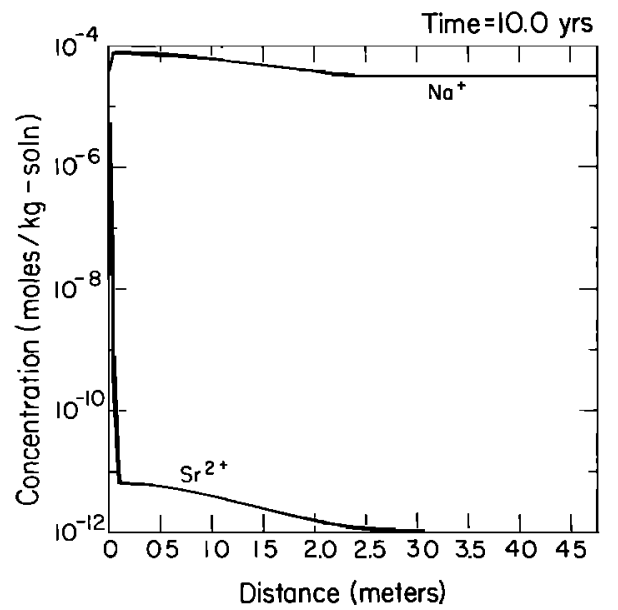

Fig. 3d. Transport of $\mathrm{Sr}^{2+}$ in background solution of $3 \times 10^{-5} \mathrm{M}$ $\mathrm{NaCl}$ after 10 years including sorption on clay; concentration of $\mathrm{Na}^{+}$ is also plotted. 


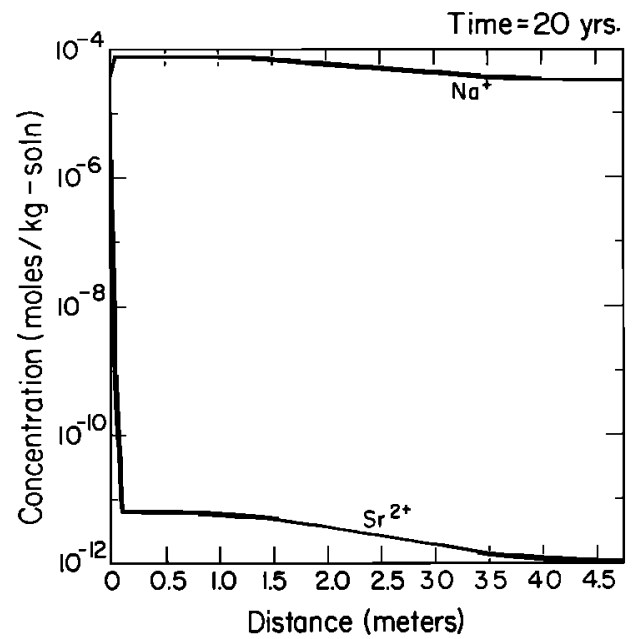

Fig. 4. Transport of $\mathrm{Sr}^{2+}$ in background solution of $3 \times 10^{-5} \mathrm{M}$ $\mathrm{NaCl}$ including sorption on clay after 20 years; concentration of $\mathrm{Na}^{+}$ is also plotted.

than its initial concentration in the supporting electrolyte at significant distances ahead of where it had been totally sorbed in Figure 2. In Figures $3 d$ and 4 the aqueous concentration of $\mathrm{Sr}^{2+}$ is plotted as a function of distance at 10 and 20 years, respectively, again illustrating this effect.

Groundwaters generally contain several cations other than sodium which compete with strontium and with each other for exchange sites. To examine the effects of this phenomenon a third cation, $\mathrm{Ca}^{2+}$, was added to the supporting electrolyte mixture in amounts consistent with its occurrence in natural ground waters (Table 1). Figures $5 a$ and $5 b$ illustrate the effects of adding this third sorbable ion to the aqueous system. The reactions 1, 2, and 3 (Table 2) are pertinent. (Note that each of these reactions involves aqueous and sorbed hydrogen ions. Equilibrium constants for exchange reactions between the other cations, $\mathrm{Na}^{+}, \mathrm{Sr}^{2+}$, and $\mathrm{Ca}^{2+}$, are computed by combining appropriate pairs of these reactions; therefore the concentrations of aqueous and sorbed hydrogen ions cancel out of the computations.)

Table 1 shows that the calculated $k_{D}$ have been reduced by addition of $\mathrm{Ca}^{2+}$. For $10^{-3} \mathrm{M} \mathrm{Na}{ }^{+}$, the boundary $k_{D}$ of strontium is reduced from about 1900 to approximately 50 when a concentration of $10^{-3} \mathrm{M} \mathrm{Ca}^{2+}$ is added to the ground

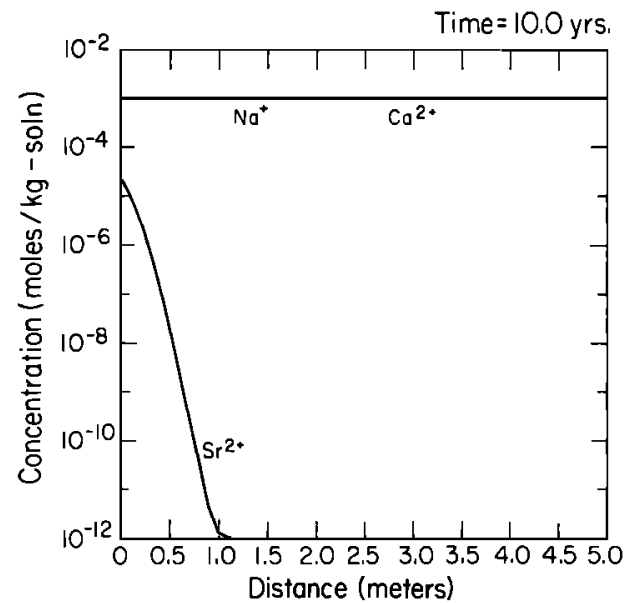

Fig. 5a. Transport of $\mathrm{Sr}^{2+}$ in background solution of $10^{-3} \mathrm{M}$ $\mathrm{NaCl}$ and $10^{-3} \mathrm{M} \mathrm{CaCl}_{2}$ including sorption on clay; concentrations of $\mathrm{Na}^{+}$and $\mathrm{Ca}^{2+}$ are also plotted.

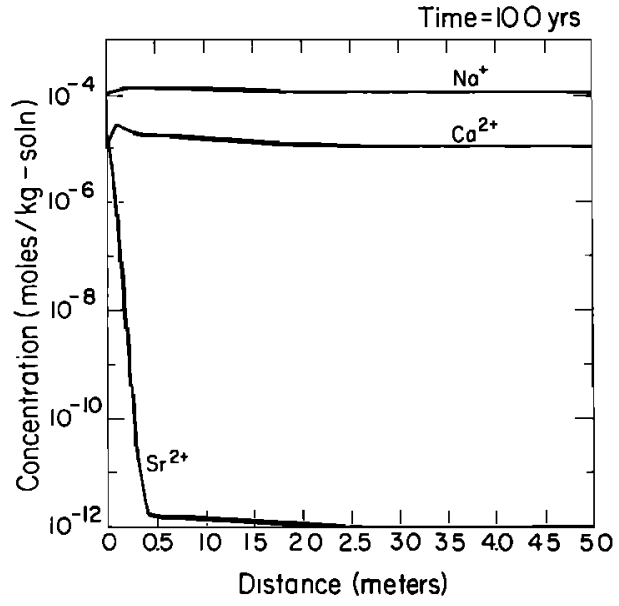

Fig. 5b. Transport of $\mathrm{Sr}^{2+}$ in background solution of $10^{-4} \mathrm{M}$ $\mathrm{NaCl}$ and $10^{-5} \mathrm{CaCl}_{2}$ including sorption on clay; concentrations of $\mathrm{Na}^{+}$and $\mathrm{Ca}^{2+}$ are also plotted.

water because of the competition of the different species for the sites on the solid. To use a $k_{D}$ type of model for prediction of contaminant transport, one must measure a $k_{D}$ for the exact conditions of the expected groundwater. Because the groundwater composition can change due to the reaction of the wasteform with it, the $k_{D}$ type of model cannot predict contaminant transport accurately, as already suggested by Reardon [1981].

When $\mathrm{Ca}^{2+}$ is omitted from the supporting electrolyte, sorption of $\mathrm{Sr}^{2+}$ causes the strontium concentration in the aqueous phase to drop to its initial value $\left(10^{-12} \mathrm{M}\right)$ at a distance of $0.1 \mathrm{~m}$ after ten years. However, the addition of $10^{-3}$ $\mathrm{M} \mathrm{Ca}^{2+}$ lowers the degree of strontium sorption such that the aqueous $\mathrm{Sr}^{2+}$ concentration remains above its initial value for a full meter after ten years.

It is also interesting to note that when both $\mathrm{Na}^{+}$and $\mathrm{Ca}^{2+}$ are present in the groundwater, the clay sites are largely occupied by calcium. For a groundwater containing $10^{-4} \mathrm{M} \mathrm{Na}^{+}$ and $10^{-5} \mathrm{M} \mathrm{Ca}^{2+}, \mathrm{Ca}^{2+}$ occupies about 100 sites to each site occupied by $\mathrm{Na}^{+}$. Therefore, when $\mathrm{Sr}^{2+}$ is sorbed, $\mathrm{Ca}^{2+}$ is the ion which is principally displaced (see Figure $5 b$ ). This increase in the aqueous phase concentration of $\mathrm{Ca}^{2+}$ leads again to the enhanced concentration effect observed in the case of binary exchange (Figures 3 and 4). The depleted level of $\mathrm{Sr}^{2+}$ must now compete with an increased $\mathrm{Ca}^{2+}$ concentration downstream, resulting in $\mathrm{Sr}^{2+}$ moving ahead of the steep sorption front.

The ions in the aqueous phase can also form complexes. It is possible for a contaminant to move downstream from the canister to much greater distances and at much greater rates in a complexed state than the bare ion can move, especially if that complex is uncharged or negatively charged. To illustrate the effects of complexation, equilibrium constants for formation of $\mathrm{SrCO}_{3}{ }^{\circ}$ and $\mathrm{NaCO}_{3}{ }^{-}$were added to the data base. Activity coefficients of solute species were calculated using the Davies equation. Figure $6 a$ is a plot of the concentrations of bare ions $\left(\mathrm{Sr}^{2+}\right.$ and $\left.\mathrm{Na}^{+}\right)$in the aqueous phase as a function of distance after 5 years for the binary ion exchange case with the complexes $\mathrm{SrCO}_{3}{ }^{\circ}$ and $\mathrm{NaCO}_{3}{ }^{-}$forming in the aqueous phase (reactions 1, 2, 4, and 7 of Table 2). Concentrations of the complexes $\left(\mathrm{SrCO}_{3}{ }^{\circ}\right.$ and $\left.\mathrm{NaCO}_{3}{ }^{-}\right)$are plotted in Figure $6 \mathrm{~b}$ as a function of distance. The relative concentrations of these particular complexes are not particularly high. However, the effect of complexation on the transport of strontium is evident in 


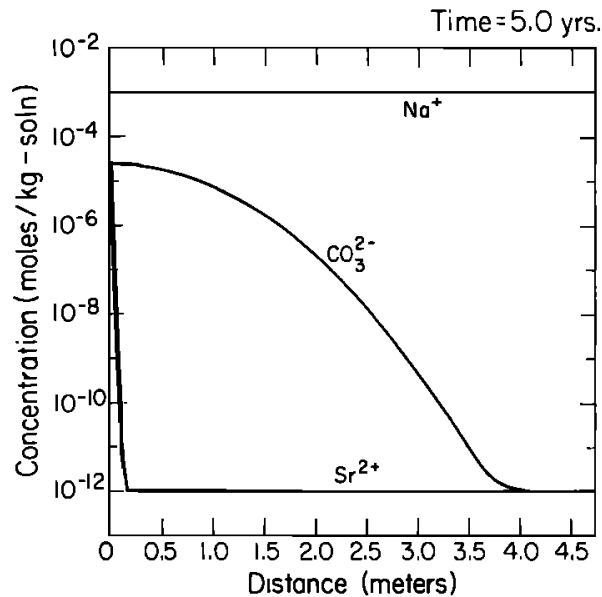

Fig. 6a. Transport of $\mathrm{Sr}^{2+}$ in background solution of $10^{-3} \mathrm{M}$ $\mathrm{NaCl}$ including complexation and sorption; concentrations of $\mathrm{Na}^{+}$ and $\mathrm{CO}_{3}{ }^{2-}$ are also plotted.

Figure $6 b$, where a low, broad front of the strontium complex exists far in advance of the relatively sharp front of the bare ion $\mathrm{Sr}^{2+}$ (Figure 6a). Although the concentration of $\mathrm{Sr}^{2+}$ may be low, the concentration of the complex $\mathrm{SrCO}_{3}{ }^{0}$ depends on the concentration of both $\mathrm{Sr}^{2+}$ and $\mathrm{CO}_{3}{ }^{2-}$. If the level of $\mathrm{CO}_{3}{ }^{2-}$ is high, the transport of $\mathrm{SrCO}_{3}{ }^{\circ}$ can be important. The magnitude of the enhanced concentration effect due to complexation is certainly trivial in this system; however, certain other elements can exist in highly complexed states, e.g., the actinides. In such highly complexed systems this effect may significantly affect their migration.

Inclusion of the dissociation of water can have significant effects on the mobility of certain solute species. Complexes such as $\mathrm{HCO}_{3}{ }^{-}, \mathrm{H}_{2} \mathrm{CO}_{3}{ }^{\circ}, \mathrm{SrOH}^{+}, \mathrm{NaHCO}_{3}{ }^{\circ}$ and $\mathrm{NaOH}^{0}$ can be more realistically treated. The formation of these complexes affects the hydrogen ion balance $(\mathrm{pH})$ in the aqueous phase which, in turn, affects the solubilities of contaminant-bearing solids, their kinetics of dissolution, and the hydrogen ion concentration on exchange sites.

Figures $7 a$ and $7 b$ illustrate the effects of both dissociation of water and complexation on the transport of strontium. Reactions $1,2,4,5,7-11,15$, and 16 were modeled. One effect is that a $p \mathrm{H}$ of approximately 10 is maintained near the boundary despite the fact that the initial $p \mathrm{H}$ was varied from 6 to 10 . This buffering effect is principally due to the strontianite activity

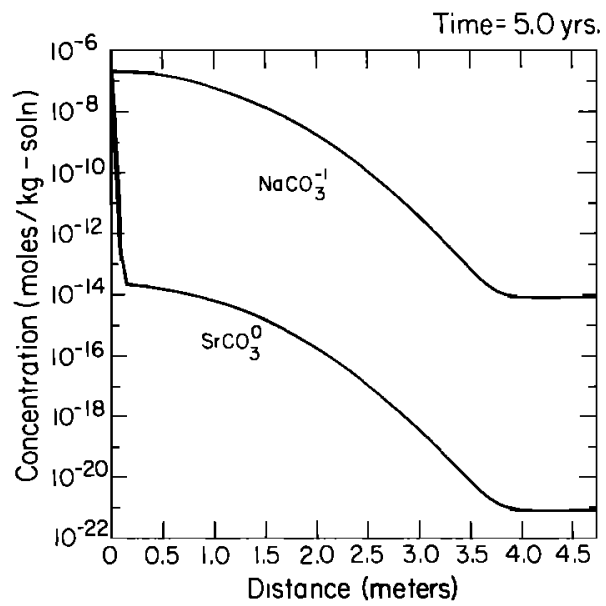

Fig. $6 b$. Transport of complexes corresponding to Figure $6 a$.

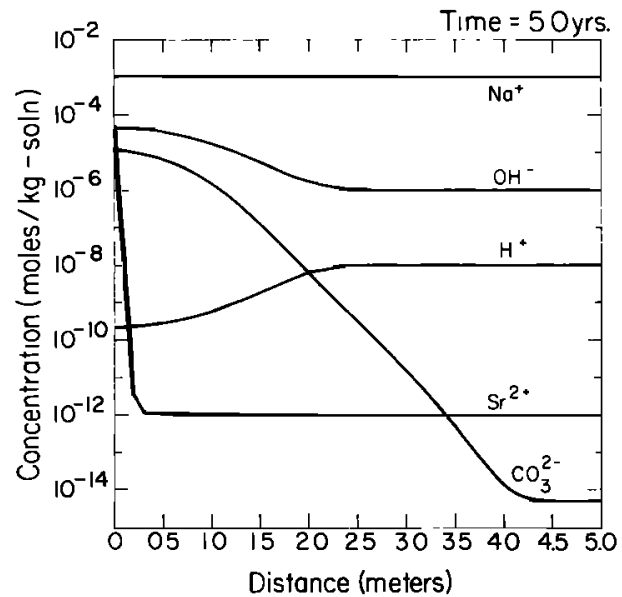

Fig. 7a. Transport of $\mathrm{Sr}^{2+}$ in background solution of $10^{-3} \mathrm{M} \mathrm{NaCl}$ including complexation, water dissociation, and sorption; concentrations of $\mathrm{Na}^{+}, \mathrm{H}^{+}, \mathrm{CO}_{3}{ }^{2-}$, and $\mathrm{OH}^{-}$are also plotted.

product constraint coupled with $\mathrm{HCO}_{3}{ }^{-} / \mathrm{CO}_{3}{ }^{2-}$ equilibrium. It is an effect of fundamental importance, since it suggests that the wasteform can control certain facets of its surrounding chemical environment.

Accounting for the dissociation of water also allows the solution $p \mathrm{H}$ to vary as a function of transport distance. Therefore the amounts of $\mathrm{OH}^{-}$and $\mathrm{CO}_{3}{ }^{2-}$ available for complexation also vary in a realistic manner, affecting the amounts of these species available for complexation with strontium (Figure $7 b$ ). The effect of varying $p \mathrm{H}$ on the mobility of strontium is negligible in this system, since strontium is never strongly complexed, but the effect of $p \mathrm{H}$ variation on the mobility of the actinides could well be significant.

Figures $8 a$ and $8 b$ show concentrations of bare ions and complexes respectively as functions of distance after five years for a more complex case: a ternary ion exchange process with an increased number of complexes and an initial carbonate content more typical of a groundwater system. All reactions in Table 2 were used for this case. The complex $\mathrm{SrHCO}_{3}{ }^{+}$has also been included for this calculation. The formation constant for strontium bicarbonate is not well known. However, to get at least some idea of its importance, we used a value for the formation constant of $\mathrm{SrHCO}_{3}{ }^{+}$similar to that of $\mathrm{CAHCO}_{3}{ }^{+}$ [Ball et al., 1980]. Again, the $p \mathrm{H}$ near the waste canister is buffered, this time to a value near 9 , even though the initial

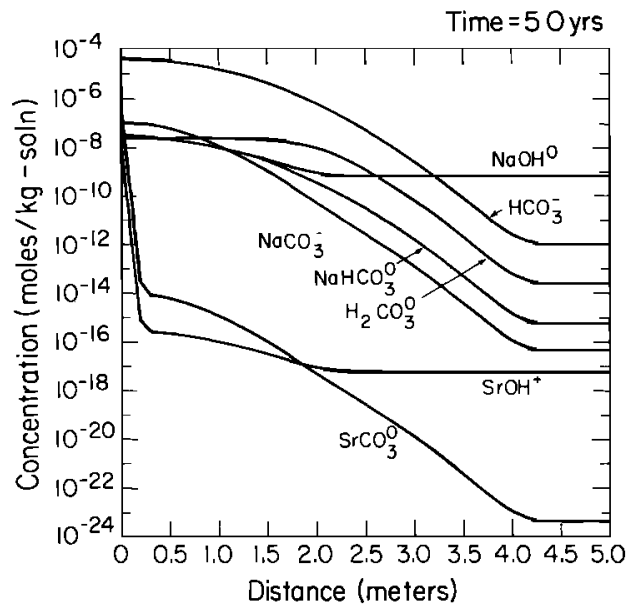

Fig. $7 b$. Transport of complexes corresponding to Figure $7 a$. 


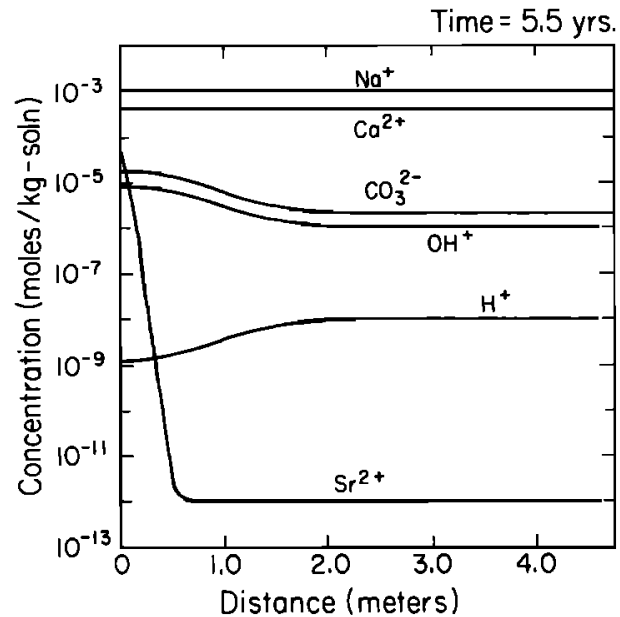

Fig. 8a. Transport of $\mathrm{Sr}^{2+}$ for a background solution similar to a typical groundwater system.

carbonate content is now $5 \times 10^{-3} \mathrm{M}$ instead of $10^{-12} \mathrm{M}$. The strontium is transported farther downstream in this case because of increased amounts of the calcium ion.

\section{Summary aNd Conclusions}

CHEMTRN, a transport model which accounts for many equilibrium chemical processes common to hydrochemical systems, has been developed and applied to a hypothetical study of contaminant transport. CHEMTRN provides for complexation in the aqueous phase and treats sorption as an equilibrium ion exchange process. The ion exchange algorithm specifies a constant finite surficial density of exchange sites and accounts for competition among different cationic species for occupancy of those sites. CHEMTRN also includes algorithms describing the dissociation of water and the nonideality of both sorbed and solute species.

Several calculations were made with CHEMTRN in order to determine the necessity for inclusion of specific chemical processes in this and other models used to predict contaminant transport. The hypothetical waste disposal system consisted of a strontianite waste form surrounded by a water-saturated porous backfill composed of montmorillonite. From the results of these calculations, several conclusions can be drawn.

1. When the concentration of a positively charged contaminent such as $\mathrm{Sr}^{2+}$ is extremely small, relative to the con-

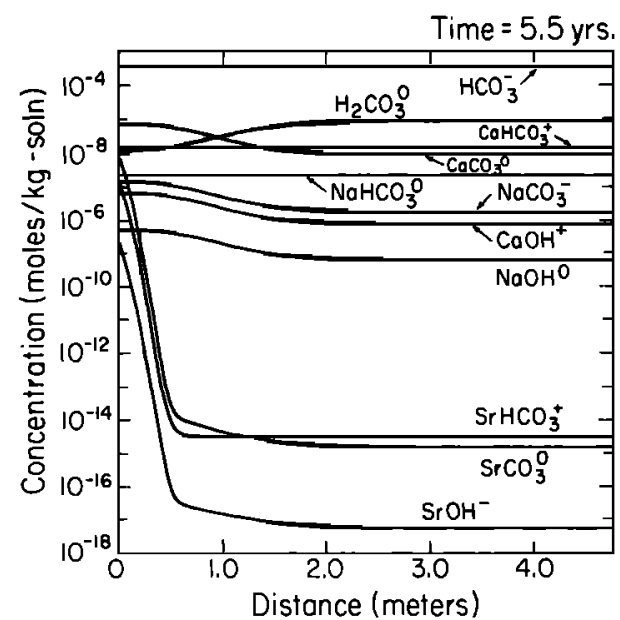

Fig. 8b. Transport of complexes corresponding to Figure $8 a$. centration of the supporting electrolyte (e.g., $\mathrm{NaCl}$ ) and the CEC of the sorbing material, the distribution coefficient $\left(k_{D}\right)$ of the trace ion is constant. If the wasteform does not alter the groundwater composition, a $k_{D}$ model can in most cases be used to simulate the transport of this trace ion. However, the distribution coefficient should be measured or calculated in a manner designed to duplicate exactly the situation expected to exist in the near-wasteform region at the time of loss of wasteform integrity. In addition, it should be noted that the definition of 'trace' for each cation of interest should be determined experimentally.

2. When the concentration of the contaminant is comparable to the concentration of the supporting electrolyte, a constant distribution coefficient model is inadequate to simulate the mass transport process. This fact is evidenced by the orders of magnitude difference in the value of the distribution coefficient calculated to exist across the moving solute front.

3. Migration of a nontrace contaminant far ahead of where it is initially strongly sorbed was found to occur when surface site constraints were accounted for in the model. This phenomenon is not adequately accounted for in models which employ constant distribution coefficients.

4. When the scope of the model was broadened to account for competition for a fixed number of surface sites by more than two species, a significantly greater degree of mobility of strontium was noted.

5. Incorporation of aqueous complexation in the model does not significantly enhance the mobility of strontium, but the calculation does serve to illustrate qualitatively the importance of such phenomena. Other radionuclides, such as the actinides, may be strongly complexed in groundwater to the point that only a minimal fraction of the element may exist as positively charged species [Langmuir, 1978]. Therefore the incorporation of complexation phenomena in models of toxic waste transport appears to be a necessity for these radionuclides.

6. Allowing water to dissociate resulted in profound effects on the chemistry of the system. The dissociation of water coupled with boundary solubility constraint buffered the $\mathrm{pH}$ of the ground water near the wasteform to a value between 9 and 10 regardless of the initial value of the groundwater $p H$. In addition, the inclusion of the dissociation of water allows $p \mathrm{H}$ to vary along the transport path. This, in turn, causes changes in the amount and type of complexes formed and the amount of sorption possible.

CHEMTRN has recently been modified to account for chemical precipitation phenomena. In addition, a model of sorption which includes surface ionization and complexation has also been included as an alternative to the ion exchange model. This option provides a more realistic treatment of earth materials whose surficial site density is not constant but is a function of $p \mathrm{H}$. The effects of these additional chemical mechanisms on contaminant transport will be reported in the near future.

Acknowledgments. We would like to thank our colleague Chalon Carnahan for many stimulating conversations and for reviewing this manuscript. We would also like to acknowledge access to an unfinished computer program generated by P. Lichtner, who was working on solving the chemical transport problem using a different approach from the one discussed in this paper. This work was supported by the Division of Safeguards, Fuel Cycle and Environmental Research of the Office of Nuclear Regulatory Research, U.S. Nuclear Regulatory Commission with the U.S. Department of Energy under contract DEAC03-76SF00098 and by N.R.C. FIN B-3040-0 under Interagency Agreement DOE 50-80-97. 


\section{REFERENCES}

Ahlstrom, S. W., H. P. Foote, R. C. Arrett, C. R. Cole, and R. J. Serne, Multicomponent mass transport model, Rep. BWL-2127, Batelle Northwest Laboratory, Richland, Washington, 1977.

Anderson, M. P., Using models to simulate the movement of contaminants through groundwater flow systems, CRC Critical Rev. Environ. Control, 9(2), 97-156, 1979.

Ball, J. W., D. K. Nordstrum, and E. A. Jenne, Additional and revised thermochemical data and computer code for WATEQ2: A computerized chemical model for trace and major element speciation and mineral equilibria of natural waters, U.S. Geol. Surv. Water Resour. Invest. 78-116, 1980.

Benson, L. V., A tabulation and evaluation of ion exchange data on smectites, certain zeolites and basalt, Lawrence Berkeley Lab. Rep. LBL 10541, Natl. Tech. Inform. Serv., Springfield, Va., 1980.

Benson, L. V., and L. S. Teague, A tabulation of thermodynamic data for reactions involving 58 elements common to radioactive waste package systems, Lawrence Berkeley Lab. Rep. LBL-11448, Natl. Tech. Inform. Serv., Springfield, Va., 1980.

Bodvarsson, G. S., Mathematical modelling of the behavior of geothermal systems under explotation, Lawrence Berkeley Lab. Rep. LBL13937, Natl. Tech. Inform. Serv., Springfield, Va., 1981.

Charbeneau, R. J., Groundwater contaminant transport with adsorption and ion exchange chemistry, method of characteristics for the case without dispersion, Water Resour. Res., 17(3), 705-713, 1981.

Charbeneau, R. J., and R. L. Street, Finite element modeling of injection-extraction systems, Tech. Rep. 231, Dep. of Civ. Eng., Stanford Univ., Stanford, Calif., 1978.

Davis, J. A., R. O. James, and J. O. Leckie, Surface ionization and complexation at the oxide/water interface, 1 , Computation of electrical double layer properties in simple electrolytes, J. Colloid Interface Sci., 63(3), 480-499, 1978.

Grove, D. B., and W. W. Wood, Prediction and field verification subsurface-water quality changes during artifical recharge, Lubbock, Texas, Ground Water, 17(3), 250-257, 1979.

Hindmarsh, A. C., Solution of block-tridiagonal systems of linear equations, Rep. UCID-30150, Lawrence Livermore Lab., Livermore, Calif., 1977.

Hindmarsh, A. C., LSODE and LSODI, Two new initial value differential equation solvers, Assoc. Comput. Mach. SIGNUM Newsletter, 15(4), 10-11, 1980.

Holly, 'D. E., and P. R. Fenske, Transport of dissolved chemical con- taminants in groundwater systems, Geol. Soc. Am. Mem., 110, 171$183,1968$.

Kee, R. J., and J. A. Miller, A computational model for chemically reacting flow in boundary layers, shear layers, and ducts, Rep. SAND81-8241, Sandia Natl. Lab., Livermore, Calir., 1981.

Langmuir, D., Uranium solution mineral-equilibria at low temperatures with applications to sedimentary ore deposits, Geochim. Cosmochim. Acta, 42, 547-569, 1978.

Petzold, L. R., Differential/algebraic equations are not ODE's, Rep. SAND81-8668, Sandi Natl. Lab., Livermore, Calif., 1981.

Reardon, E. J., $\mathbf{K}_{d}$ 's-Can they be used to describe reversible ion sorption reactions in contaminant migration?, Ground Water, 19(3), 279-286, 1981.

Roberts, P. V., P. McCarty, and W. Roman, Direct injection of reclaimed water into an aquifer, J. Environ. Eng. Div., Am. Soc. Civ. Eng., I04(EE5), 933-949, 1978.

Rouston, R. C., and R. J. Serne, One-dimensional model of the movement of trace radioactive solute through soil columns: The percol model, Rep. BNWL-1918 Battelle Northwest Lab., Richland, Wash., 1972.

Rubin, J., and R. V. James, Dispersion-affected transport of reacting solutes in saturated porous media: Galerkin method applied to equilibrium-controlled exchange in unidirectional steady water flow, Water Resour. Res., 9, 1332-1356, 1973.

Strickert, R., A. M. Friedman, and S. Fried, ARDISC (Argonne Dispersion Pr Code): Computer programs to calculate the distribution of trace element migration in partially equilibrating media, Argonne Natl. Lab. Rep. ANL-79-25, Natl. Tech. Inform. Serv., Springfield, Va., 1979.

Stumm, W., and J. J. Morgan, Aquatic Chemistry, Wiley-Interscience, New York, 1970.

Valocchi, E. J., R. L. Street, and P. V. Roberts, Transport of ionexchanging solutes in ground water: chromatographic theory and field simulation, Water Resour. Res., 17(5), 1517-1527, 1981.

Walsh, M. P., L. W. Lake, and R. S. Schecter, A description of chemical precipitation mechanisms and their role in formation damage during stimulation by hydrofluoric acid, paper presented at 1982 International Symposium on Oilfield and Geothermal Chemıstry, Society of Petroleum Engineers, Dallas, Texas, Jạn. 25-27, 1982.

(Received January 27, 1982; revised September 28, 1982; accepted Novernber 17, 1982.) 